\title{
Pity: a qualitative study on Iranian women with breast cancer
}

This article was published in the following Dove Medical Press journal:

Patient Preference and Adherence

\section{Sharareh Zeighami \\ Mohammadi \\ Sima Mohammadkhan \\ Kermanshahi \\ Zohreh Vanaki}

Department of Nursing, Faculty of Medical Sciences, Tarbiat Modares

University, Tehran, Iran
Correspondence: Sima Mohammadkhan Kermanshahi

Department of Nursing, Faculty of Medical Sciences, Tarbiat Modares University, Al Ahmad Street, Jalal AleAhmad, Nasr, PO Box I4I I5-I II,

Tehran, Iran

Tel/fax+98218288 3899

Email kerman_s@madares.ac.ir
Background: Women with breast cancer (BC) are commonly confronted with others' pity. However, there is limited information about pity in Iranian women with BC. The aim of this study was to explore perceptions, reactions, coping strategies, and consequences of pity among Iranian women with BC.

Methods: This qualitative study was carried out from March 2016 till October 2017. A purposive sample of 36 women with $\mathrm{BC}$ was selected with maximum variation from three health care centers in Alborz Province, Iran. Data were collected using semistructured interviews and analyzed using a conventional content-analysis approach.

Results: Our findings indicated that Iranian women with BC experienced received pity and perceived unusual attention from others as due to certain reasons. Others' pity caused negative emotional reactions in them. They used self-protection strategies against others' pity. The consequences of self-protection against pity were normalizing the patient's flow of life and/or social isolation.

Conclusion: Pity is a serious psychosocial challenge in Iranian women with BC, with negative effects on quality of life. Therefore, pity should be considered in counseling and psychosocial screening of patients.

Keywords: breast cancer, pity, qualitative study, conventional content analysis

\section{Introduction}

Breast cancer $(\mathrm{BC})$ is the most common cancer in women worldwide. According to GLOBOCAN 2018 report, 2.1 million new BC cases are diagnosed annually around the world. ${ }^{1} \mathrm{BC}$ with an incidence rate of 33.2 per 100,000 is the most prevalent cancer in Iranian women. ${ }^{2}$ Diagnosis and treatment of BC cause emotional distress in patients. Therefore, providing emotional support is one of the most important needs of women with BC. ${ }^{3,4}$ Emotional support in women with BC requires maintaining social interaction and communication skills. ${ }^{3}$ Women with BC experience empathy and sympathy during social interactions. Empathy and sympathy are synonymous with each other and often used interchangeably, but they are seriously different from each other. ${ }^{5}$

Sympathy is defined as feelings of pity and sorrow for someone else's misfortune, without trying to solve the person's problem. However, empathy refers to the ability to understand and share the feeling of another person's emotion. ${ }^{6,7}$ Empathy is a most important component of relationships with cancer patients and affects self-confidence, hope, and psychosocial adjustment. ${ }^{7-10}$

Most studies have focused on the positive aspects of social interactions, with few on social interaction problems in cancer patients. ${ }^{7}$ Several studies have shown that women with $\mathrm{BC}$ experience pity,,$^{3,7,10,11}$ and worry about others' pity was one of their 
main interpersonal interaction difficulties. ${ }^{11,12}$ Pity led to anger, fear, vulnerability, ${ }^{7}$ social isolation, and poor coping with cancer. ${ }^{10,11}$

Cultural differences affect emotional responses to cancer. ${ }^{13}$ Furthermore cancer-related taboos and stigma affect social relationships with cancer patients. ${ }^{14,15}$ Iranians believe that cancer equals death, pain, and loss of function. Also, Iranian family members and health care providers, through nondisclosure of the patient's diagnosis, avoid the using the Persian word for "cancer" in front of the patient and patients must hide their illness from others. ${ }^{14}$ Pity is a psychosocial challenge for Iranian women with BC. However, few studies have been done about pity in women with BC. ${ }^{6} 16$ Therefore, the aim of this study was to explore perceptions, reactions, strategies, and consequences of pity among Iranian $\mathrm{BC}$ women.

\section{Methods}

Participants were selected using purposeful sampling and maximum variation. Inclusion criteria confirmed the diagnosis of $\mathrm{BC}$, age 18 years or older, ability to communicate verbally in Persian, experiences of pity, and willingness to share them. A sample of 36 women with $\mathrm{BC}$, were recruited from three health care centers affiliated with Alborz University of Medical Sciences, Karaj, Iran. Table 1 shows participant characteristics.

\section{Data gathering}

Participants were interviewed from March 2016 till October 2017, with questions including "Please tell me, who knows about your disease?" and "Explain how people react to your disease". Then, according to participants' responses and the aims and approach of the study, interviews were continued with specific questions, such as "When?",

Table I Participant characteristics $(n=36)$

\begin{tabular}{|l|l|}
\hline Age (years) & 24-64 \\
\hline Marital status & Single 4, married 25, divorced 5, widowed 2 \\
\hline Number of children & $\begin{array}{l}\text { No child 6, one child 7, two children 19, more } \\
\text { than two children 4 }\end{array}$ \\
\hline Educational level & $\begin{array}{l}\text { Below diploma 3, diploma 13, bachelor's } \\
\text { degree II, master's degree 6, PhD 3 }\end{array}$ \\
\hline $\begin{array}{l}\text { Current } \\
\text { occupational status }\end{array}$ & $\begin{array}{l}\text { Housewife I4, retired 2, unemployed due to } \\
\text { illness 8, employed part-time 4, employed } \\
\text { full-time 8 }\end{array}$ \\
\hline Cancer stage & I 8, II I4, III 7, IV 7 \\
\hline Surgery type & Lumpectomy I5, mastectomy 2I \\
\hline $\begin{array}{l}\text { Patient status during } \\
\text { interview }\end{array}$ & $\begin{array}{l}\text { Surgery 3, chemotherapy 6, radiotherapy 6, } \\
\text { hormone therapy I0, survivor II }\end{array}$ \\
\hline
\end{tabular}

"Why?", "How do you feel about that?", "What did you do?", "What was the result?", and "Can you explain more?" All interviews were held by the first author in a private and quiet room at patients' homes. Face-to-face, semistructured interviews lasted 30-120 minutes, based on patients' preferences. All interviews were recorded after permission of the interviewees. Interviews continued until data saturation, and researchers did not receive a new code in the last three interviews.

\section{Data analysis}

Data analysis was based on a conventional content-analysis approach defined by Graneheim and Lundman. ${ }^{17}$ Data analysis and data collection were performed concurrently. Analysis was conducted immediately after interviews. The first author (SZM) listened to the recorded interviews and transcribed them word by word. Each interview transcript was analyzed. Each transcribed interview was reviewed several times so the researcher was immersed in the data and achieved a holistic sense of participants' experiences. "Meaning units" (ie, words, sentences, or paragraphs) were extracted, abstracted, and labeled with a code. Different codes were classified based on differences and similarities and formed subcategories. Similar subcategories formed the main categories with a higher level of abstraction. Codes, subcategories, and main categories were determined by agreement between the second (SMK) and third authors (ZV). Finally, codes were sorted into nineteen subcategories and six main categories.

\section{Trustworthiness}

To increase the rigor of the study, we used Cuba and Lincoln's criteria for credibility, dependability, transferability, and conformability. ${ }^{18}$ Credibility was attained through prolonged engagement with the data, with study members and peers checking. Two nursing-faculty members who were experts in qualitative research (ie, the second and third authors) supervised and evaluated the interviews and analyzed (codes and categories) and improved dependability and conformability. Transferability of the findings was strengthened using maximum-variation sampling.

\section{Ethical considerations}

The ethics committee of Tarbiat Modares University approved the study (code 52D8050). Participants were told about the purpose of the research. Verbal and written informed consent for participation and sound recording was obtained from all participants. They were assured of the 
confidentiality of the sound files and the interview transcripts. Participants were aware of the right to leave the study at any stage. This study was conducted in accordance with the Declaration of Helsinki.

\section{Results}

Participants in this study were 36 women with BC (Table 1). The six main categories to emerge from the data were perceptions (receiving/perceiving unusual attention, perceived reasons behind pity), reactions (negative emotional reactions), strategy (self-protection), and consequences (normalization of the flow of life and/or social isolation) (Table 2).

\section{Receiving/perceiving unusual attention}

Participants experienced pity from others as excessive, exaggerated, unusual, and different from conventional attention and affection, with two main characteristics: excessive compassion and unempathic interactions.

\section{Excessive compassion}

Participants felt pity from others from the tone of speech and the sympathetic words of surrounding people. The patient felt this pity when people pretended they were upset due to the cancer and at the time of expressing their sympathy, their tone was sad and stereotypical:

In my last chemotherapy session, all other patients in the chemotherapy unit were old, and I was the only young patient receiving chemotherapy there. Every person who

Table 2 Categories and subcategories of data

\begin{tabular}{|l|l|}
\hline Main categories & Subcategories \\
\hline $\begin{array}{l}\text { Receiving/perceiving } \\
\text { unusual attention }\end{array}$ & $\begin{array}{l}\text { Extreme compassion } \\
\text { Unempathic interaction }\end{array}$ \\
\hline behind pity & $\begin{array}{l}\text { Beliefs about illness } \\
\text { The deadly nature of the disease } \\
\text { Changes in physical appearance } \\
\text { Limited physical functioning }\end{array}$ \\
\hline Negative emotional & $\begin{array}{l}\text { Oversensitivity to pity } \\
\text { Anger } \\
\text { Irritation and discomfort } \\
\text { A sense of humility } \\
\text { A sense of approaching an imminent death }\end{array}$ \\
\hline Self-protection & $\begin{array}{l}\text { Optimism } \\
\text { Intentional disregard } \\
\text { Avoidance of social interactions } \\
\text { Concealment }\end{array}$ \\
\hline Normalization the \\
flow of life
\end{tabular}

was in the unit pitied me with a sad voice and used such words as "Oh my God, look how young this patient is", "What a torture you are suffering!", "Why you? Why did you become ill? Why are you receiving chemotherapy? What happened to you?" [P4]

Behaviors of relatives and friends during visits were perceived as pity by participants. Relatives and friends repeatedly visited the patients. They were trying not to talk about cancer and attempted to do things to make the patient happy. Also, most of the time, visitors wept and sympathized.

When they came to visit me, they looked at me and started to cry. Such pathetic looks and behaviors annoyed me extremely. [P7]

Extreme and unusual kindness and compassion, frequent phone calls, and perceived excessive considerateness were also perceived as pity by BC patients. Some of the behaviors they experienced as pity were to avoid competing with the patient and pretending to be compassionate, not asking the patient to help others at parties and ceremonies, an artificially calm atmosphere around the patient, avoidance of discussing life's tensions with the patient, and paying too much attention to the patient:

Before cancer, some people might be unkind and jealous to you and attempt to hurt you. However, after cancer affliction, you see them visit you frequently and want to be kind to you. I think this is the pity. I think that extreme and unordinary kindness is the pity. [P3]

When the family gets into trouble at home, they will not tell me. Regularly, I hear that they say slowly, "Be careful, she is sick, she has cancer". Everything changed, became artificial, and out of normal mode. I had already discussed and squabbled with my mother, but now they all finished the debate and say that it's right for you. I know it's due to my condition. I do not like this pity. [P4]

There is a time that I'm complaining, but I see that my husband does not react and does not say anything because I had cancer. I think he pities me. [P21]

The patients perceived pity in the eyes of the people around them:

During the chemotherapy days, we went to a family party. All people tried to show usual behavior toward me. They wanted me to do a special dance, but in the middle of the dance, I experienced dizziness and failed and I couldn't complete it. All of them said, "Sit down! Sit down! It's enough. Thanks a lot." There, I felt a sense of powerlessness. Their eyes looked at me with pity. [P7] 


\section{Unempathic interaction}

Participants perceived pity as a sympathetic reaction that is false, superficial, and without honesty and empathy. Pious words were emotional, but they did not reflect the true inner feelings of the individual and conflicted with them. Also, they were unrealistic, disrespectful, and even hurtful. The participants believed that pity was immoral: far from humanity and the inner well-being of the patient:

I felt that she was looking at me from a superior position because she was healthy. Seemingly, she sympathized with me, but her behavior was not truthful. She just used deceiving words, such as "Oh, poor thing" or "Oh, my dear". She just wanted to obtain more information and know more about me. I think those with pathetic behaviors are not human. [P4]

Participants experienced that pity was not helpful, not supportive, and did not help to improve feelings or reduce the patients' suffering:

My sisters-in-law frequently called me on the phone and asked many questions about my illness and its treatments. None of them called me to ask about my health status or support me. Such pity was not helpful for me. I liked that they asked me about what they could do for me or give hope to me. [P30]

Most of the time, relatives played a compassionate role. $[\mathrm{P} 15]$

\section{Perceived reasons behind pity}

The four subcategories of this category were beliefs about illness, the deadly nature of the disease, changes in physical appearance, and limited physical functioning.

\section{Beliefs about illness}

Participants experienced others' pity because of the painful and deadly "destiny that God had ordained for them". Families and relatives of patients believed that cancer was a punishment for the patients' past sins and that she had been selected by God for this punishment. This belief has caused people regularly to ask about what the patient or her family has done that resulted in cancer:

During chemotherapy, my skeletal pains were so severe that I could not even stand on my feet. In such condition, my mother continually cried and told me, "Repent! Repent! This is the punishment for your sins". I answered her, "What have I done that deserves repentance? What sins have I committed that all people say this is the punishment for your sins?" [P17]

\section{Deadly nature of the disease}

The deadly nature of the disease was the other main reason behind pity for BC patients. The patient's family members and people believed that cancer was an incurable illness and equal to death. Therefore, they felt sorrow for afflicted patients and pitied them because they thought that cancer patients had lost the chance of life:

The name of cancer carries a sense of death. All people viewed me as a person who was approaching or near death; therefore, all of them cried. [P7]

\section{Changes in physical appearance}

The women experienced pity from others for loss of hair, eyelash, eyebrows, and unilateral or bilateral mastectomy.

During chemotherapy, they often told me how beautiful I had become. But I knew that I had become ugly and there was no reason to tell me that I had become beautiful. Such faulty behaviors gave me a sense that they did pity me and I hated that. [P23]

\section{Limited physical functioning}

The other reasons behind pity were inability to perform household activities and the maternal role due to physical weakness, limitations of the arms, and lymphedema. Furthermore, participants experienced pity for loss of breasts and sex hormones related to cancer treatment and also the threat to sexual life:

Women pathetically say that I was very young when my breasts were removed, and thus they asked whether my husband had sought a new marriage or not. They even said that my husband may check pornographic channels, and recommended that I check his cell phone. [P10]

\section{Negative emotional reactions}

Participants had several negative emotional reactions toward pity. These reactions were indicating oversensitivity, anger, irritation, and discomfort, a sense of humility, and a sense of approaching imminent death.

\section{Oversensitivity to pity}

Participants were weak, vulnerable, and sensitive emotionally and psychologically. They analyzed others' speeches and reactions severely and sensitively. Then, they tried to distinguish kindness from pity:

I'm sensitive to the senses that others give me. One can understand malevolent pity. One can understand the 
senses that others take and others' positive and negative energies. [P4]

\section{Anger}

Participants became angry when they encountered pity from others:

When they said how young I was, it was like pouring gasoline on a fire. It was like I was on fire and they poured gasoline and added fuel to the fire. [P4]

\section{Irritation and discomfort}

Participants also felt irritated and discomfited by others' pity and speeches:

The more they pitied me, the iller I felt. Their pity annoyed me and made my conditions worse. [P17]

\section{Sense of humility}

Others' pity caused feelings of weakness, frustration, misfortune, and humility in participants. Pity reduced self-identity, self-respect, self-worth, and self-confidence in them. Moreover, women with BC felt worthlessness, helplessness, and misery with others' pity:

I told myself how weak, poor, and menial I was because this disaster had happened just for me: others had high selfesteem, but I didn't. I continually grieved for myself. [P14] I needed to be calm, not pitied. I expected to keep my respect. People should raise their social awareness. [P15]

\section{Sense of approaching an imminent death}

Extreme kindness and cries of visitors caused the patients to feel that death was imminent:

My significant others give me kisses of death. Their kindness is so unusual that I feel I'm approaching an imminent death. [P15]

\section{Self-protection}

Participants employed strategies for protecting themselves against pity. These self-protection strategies were optimism, intentional inattention, avoidance of social interactions, and concealment of $\mathrm{BC}$ affliction.

\section{Optimism}

Participants believed that perceived pity was a misconception, an inaccurate understanding and interpretation of others' usual attention or sincere kindness. Therefore, they attempted to protect themselves against pity by changing their mind-set and improving their attitudes and interpretations. In other words, they tried to perceive pity as attention and support, rather than just pity:

Previously, I hated my friend's phone calls and thought that she wanted to pity me. However, since I have changed my mind, I consider her calls as attention and love. Also, I've started to consider my family's help as support rather than pity. [P13]

Also, participants tried to use a win-win outlook in their social interactions to retain self-respect and protect themselves against humiliation related to pity. The win-win mind-set was the belief that if you accept yourself, others also accept you and you them:

Human relationships are complex. Others accept you as much as you accept yourself. If you consider yourself a winner, then you are a winner in all people's view. Conversely, you will experience humility if you consider yourself inferior. [P14]

\section{Intentional disregard}

Another self-protection strategy by our participants was intentional disregard of pathetic looks, speeches, and behaviors:

In the pool, they often asked me why I had no breast. I simply answered that they had cut my breast off. Then, they pitied me, but I did not pay attention to their words and continued going to the pool. [P27]

\section{Avoidance of social interactions}

Participants avoided social interactions intentionally and selectively to protect themselves against pity:

I tried to escape from some certain people, ie, those who pitied me, and give them the cold shoulder. I attempted to avoid some relationships for their hurtfulness. [P17]

\section{Concealment}

The women tried to hide their cancer, negative feelings, and changes to their bodies from others to protect themselves against others' pity:

I did not tell anything to my relatives about my cancer for their inappropriate behaviors and pity. [P34]

\section{Normalization of flow of life}

Normalization of the flow of life contained two subcategories: maintaining the peace of life and maintaining normal social interactions. These two concepts represented positive results of participants' strategies against pity. 


\section{Maintaining peace of life}

Participants' experience showed that a strategy of hiding the disease and changing bodily appearance led to protection against pity and kept peace in their private lives:

I did not like pity. I hid my disease instead of letting someone hurt me and talk about my cancer, which is the main discussion of people and finally leads to loneliness. Until now, nobody noticed my illness and I was in complete peace. My state is quiet now. I live without worries. I'm calm. [P29]

\section{Maintaining normal social interactions}

Hiding the disease and bodily changes helped the patients to maintain normal social interactions. This strategy led to patient satisfaction:

It had a good effect. Everything is normal. I'm comfortable traveling with the family. Someone does not understand my illness. I do not say anything. There is no sympathy, no mercy, and everything is normal. [P18]

\section{Social isolation}

This concept had two subcategories: loneliness and deprivation of social support. This category comprised the negative results of hiding illness and restricting social interaction against pity, which were loneliness and deprivation of social support.

\section{Loneliness}

Participants who hid their illness and stayed away from others due to pity felt lonely:

I did not tell anyone about my illness. I stayed at home during my chemotherapy period and did not go out. It was like I was in a birdcage, but didn't even go out to the yard. I slept on the bed for hours, listened to sad songs, thought bad thoughts, and felt like a prisoner, awaiting release. [P19]

\section{Deprivation of social support}

In participants' experience, hiding the disease from family and friends led to them missing out on help and emotional support:

I think if relatives like my aunt's daughter knew about my illness, it would be different for me. If they pitied me, they would do something to change my mood. They were busy around me and did not allow me to stay alone in this situation. More depression and being unwell are the result of hiding my illness. [P19]

\section{Discussion}

This study aimed to explore perceptions, reactions, coping strategies, and consequences of pity among Iranian women with BC. Findings showed that women with BC experienced pity as received/perceived unusual attention from others, due to certain reasons. Others' pity caused negative emotional reactions in women. They used self-protection strategies against others' pity. The consequences of self-protection against pity were normalizing the patient's flow of life and/or social isolation.

In this study, pity was receiving/perceiving unusual attention, which included extreme compassion and unempathic interactions. Symbolic messages in social interaction lead to a negative effect on cancer patients' quality of life. ${ }^{19}$ In many cultures, pity is a common psychosocial problem of women with BC. Studies have shown that women with $\mathrm{BC}$ experience pity via the looks, ${ }^{10}$ exaggerated attention, ${ }^{4}$ words, and sentences of the people around them. ${ }^{7}$ Another feature of pity in this study was unempathic interaction. Sinclair et al showed that pity was different from empathy and compassion, such that empathy and compassion were based on understanding and tried to reduce the pain and suffering of the patient, whereas pity was noting the misery of others without trying to reduce their suffering. ${ }^{6}$ Punter also described pity as a mask that hides true inner feelings and stereotypical and cunning behavior. ${ }^{20}$

In the present study, the main causes of pity were beliefs about illness, the deadly nature of the disease, changes in physical appearance, and limited physical functioning. Beliefs about cancer derive from social taboos and stigma concerning the disease. ${ }^{14}$ Most people believed that divine justice was practiced in this world and this was the punishment of past sins. This belief was the origin of the stereotypical behavior toward the patient as a convict or victim. ${ }^{21}$ In a study by Mosher on the uncontrolled nature of the disease, its severity and deadly nature was the cause of pity toward cancer patients. ${ }^{22}$ Gunawan et al and Guillerm showed that chemotherapy-induced alopecia was associated with other's pity. ${ }^{23,24}$

Another important finding of this study was negative emotional reactions to pity in women with $\mathrm{BC}$. Women with $\mathrm{BC}$ were sensitive to pity and regularly checked the behavior of their relatives in term of pity. Pity caused anger, irritation, and discomfort and induced a sense of humility and death. This finding was consistent with other researchers' findings, which showed that pity caused anger, fear, vulnerability, and depression in women with BC. ${ }^{6,25,26}$ Pity inducing feelings of death, ${ }^{27}$ inability, and humiliation ${ }^{28}$ led to threatening 
of identity, human dignity, and self-esteem. Pity has been considered an immoral behavior, because moral sensitivity is ignored during the relationship with the patients. ${ }^{29}$

Another finding of this study was the use of self-protection strategies against pity in the women. In the present study, the women used optimism, intentional disregard, avoidance of social interactions, and concealment (disease, emotional reactions, and physical change) to protect themselves against pity. Jones's research suggested that patients with positive thinking tried to perceive empathy rather than pity. ${ }^{26}$ However, several studies on Iranian women with BC showed that pity was the main reason for using concealment and restriction of social interaction strategies. ${ }^{4,10,11}$

In this study, the consequences of strategies against pity were normalizing the flow of life and/or social isolation. Optimism, intentional disregard, and concealment helped to maintain calm in private life and continued social interactions. On the other hand, concealment and avoidance of social interactions led to social isolation. Previous studies showed that concealing disease and limiting social interactions caused loneliness and a lack of opportunity to express feelings or receive emotional support. ${ }^{7,30}$

\section{Conclusion}

Pity is a serious psychosocial challenge in Iranian women with BC, with negative effects on quality of life. Therefore, pity should be considered in counseling and psychosocial screening of patients.

\section{Implications}

Pity and its consequences should be considered by healthpolicy makers, national media, health care providers, social scientists, psychology experts, and researchers. Planning to increase the level of community awareness about pity and the principles of empathic interactions with patients is essential. Confronting pity should include counseling and screening psychosocial issues of patients. Teaching appropriate coping strategies against pity and referring patients who have been affected by pity to psychologists and social workers should be considered. The findings of this study can be used to design a questionnaire for measuring pity and its coping strategies in Iranian women with BC. It is suggested that another study be conducted to examine the effect of communication-skills training for relatives regarding perceived pity in women with BC.

\section{Limitations}

This study is not generalizable because of the small sample and purposive sampling, but its findings can help to expand the existing knowledge about the psychosocial issues of women with $\mathrm{BC}$ based on the sociocultural context.

\section{Acknowledgments}

This study was part of a $\mathrm{PhD}$ dissertation in nursing, which was directly supervised by SMK. This study was supported and financially supported by the Research Administration of Tarbiat Modares University. We would like to thank the administration for their support, as well as BC patients for their participation.

\section{Disclosure}

The authors report no conflicts of interest in this work.

\section{References}

1. Bray F, Ferlay J, Soerjomataram I, Siegel RL, Torre LA, Jemal A. Global cancer statistics 2018: GLOBOCAN estimates of incidence and mortality worldwide for 36 cancers in 185 countries. CA Cancer $J$ Clin. 2018;68(6):394-424.

2. Nafissi N, Khayamzadeh M, Zeinali Z, Pazooki D, Hosseini M, Akbari ME. Epidemiology and histopathology of breast cancer in Iran versus other Middle Eastern countries. Middle East J Cancer. 2018; 9(3):243-251.

3. Heidari S. Assessing size of social network and emotional support sources and related factors among cancer patients. Iran J Nurs Res. 2009;4(13):91-101.

4. Taleghani F, Yekta ZP, Nasrabadi AN. Coping with breast cancer in newly diagnosed Iranian women. $J$ Adv Nurs. 2006;54(3):265-272.

5. Gerdes KE. Empathy, sympathy, and pity: 21 st-century definitions and implications for practice and research. J Soc Serv Res. 2011;37(3):230-241.

6. Sinclair S, Beamer K, Hack TF, et al. Sympathy, empathy, and compassion: a grounded theory study of palliative care patients' understandings, experiences, and preferences. Palliat Med. 2017;31(5):437-447.

7. Vanaki Z, Parsa Yekta Z, Kazemnejad A, Heydarnia AR. Interpretation of support for cancer patients under chemotherapy: a qualitative research. Iran J Psychiatry Clin Psychol. 2003;9(1):53-61.

8. Khodapanahi M, Saleh Sedghpoor B, Asghar Ai M, Harrirchi I, Katibaei J. The structural relationships between social support and hope in patients with cancer. J Psychol. 2010;14:284-298.

9. Slevin ML, Nichols SE, Downer SM, et al. Emotional support for cancer patients: what do patients really want? Br J Cancer. 1996;74(8): $1275-1279$.

10. Harandy TF, Ghofranipour F, Montazeri A, et al. Health-related quality of life in Iranian breast cancer survivors: a qualitative study. Appl Res Qual Life. 2010;5(2):121-132.

11. Mehrabi E, Hajian S, Simbar M, Hoshyari M, Zayeri F. The lived experience of Iranian women confronting breast cancer diagnosis. J Caring Sci. 2016;5(1):43-55.

12. Farhat F, Othman A, El Baba G, Kattan J. Revealing a cancer diagnosis to patients: attitudes of patients, families, friends, nurses, and physicians in Lebanon - results of a cross-sectional study. Curr Oncol. 2015;22(4):264-272.

13. Al-Azri M, Al-Awisi H, Al-Rasbi S, et al. Psychosocial impact of breast cancer diagnosis among omani women. Oman Med J. 2014; 29(6):437-444.

14. Zamanzadeh V, Rahmani A, Valizadeh L. The taboo of cancer: the experiences of cancer disclosure by Iranian patients, their family members and physicians. Psych Oncology. 2013;22(2):396-402.

15. Tang PL, Mayer DK, Chou FH, Hsiao KY. The experience of cancer stigma in Taiwan: a qualitative study of female cancer patients. Arch Psychiatr Nurs. 2016;30(2):204-209. 
16. Florian V, Mikulincer M, Hirschberger G. The anatomy of a problematic emotion - the conceptualization and measurement of the experience of pity. Imagin Cognit Pers. 1999;19(1):3-25.

17. Graneheim UH, Lundman B. Qualitative content analysis in nursing research: concepts, procedures and measures to achieve trustworthiness. Nurse Educ Today. 2004;24(2):105-112.

18. Guba EG, Lincoln YS. Naturalistic Inquiry. Newbury Park, CA: Sage Publication; 1985.

19. Fife BL, Wright ER. The dimensionality of stigma: a comparison of its impact on the self of persons with HIV/AIDS and cancer. $J$ Health Soc Behav. 2000;41(1):50-67.

20. Punter D. The Literature of Pity. Edinburgh University Press; Edinburgh. 2014.

21. Knapp S, Marziliano A, Moyer A. Identity threat and stigma in cancer patients. Health Psychol Open. 2014;1(1):205510291455228.

22. Mosher CE. Effects of gender, cancer type, and smoking status on stigmatization and psychosocial responses to people with cancer. Social psychology. PhD. State University of New York at Albany; Albany. 2007.

23. Guillerm C. A Feminist Cultural Study of Identity, Hair Loss, and Chemotherapy. Ph.D. Boca Raton, FL: Florida Atlantic University; 2015.
24. Gunawan S, Broeke CT, Ven P, Arnoldussen M, Kaspers G, Mostert S. Parental experiences with chemotherapy-induced alopecia among childhood cancer patients in Indonesia. Asian Pac J Cancer Prev. 2016; 17(4):1717-1723.

25. Drageset S, Lindstrøm TC, Underlid K. Coping with breast cancer: between diagnosis and surgery. $J$ Adv Nurs. 2010;66(1):149-158.

26. Jones KM. The impact of positive thinking and empathy induction on social perceptions of cancer. Dissertation Ph.D. The University of North Dakota; Grand Forks 2016.

27. Nizamli F, Anoosheh M, Mohammadi E. Experiences of Syrian women with breast cancer regarding chemotherapy: a qualitative study. Nurs Health Sci. 2011;13(4):481-487.

28. Lamyian M, Heidarnia AR, Ahmadi F, Faghihzadeh S, Aguilarvafaie M. Women's prospect of breast cancer early detection behavior: a qualitative research. J Birjand Univ Med Sci. 2008;15(3):88-102.

29. Ackerman F. Pity as a moral concept/the morality of pity. Midwest Stud Philos. 1995;20(1):59-66.

30. Taei Z, Radfar M, Mogadam Tabrizi F, Sheikhi N. The effect of dimension of social support on hope and loneliness in patients with breast cancer. Urmia Nurs Midwifery Fac. 2015;1313(66):473-480.

\section{Publish your work in this journal}

Patient Preference and Adherence is an international, peer-reviewed, open access journal that focuses on the growing importance of patient preference and adherence throughout the therapeutic continuum. Patient satisfaction, acceptability, quality of life, compliance, persistence and their role in developing new therapeutic modalities and compounds to optimize clinical outcomes for existing disease states are major areas of interest for the journal. This journal has been accepted for indexing on PubMed Central. The manuscript management system is completely online and includes a very quick and fair peer-review system, which is all easy to use. Visit http://www dovepress.com/testimonials.php to read real quotes from published authors. 